\title{
A Linguagem como trabalho: reflexões iniciais sobre a alienação linguística
}

\author{
Language as work: initial thoughts about the linguistic alienation \\ Vitor Vieira Ferreira \\ Luiz Barros Montez \\ Universidade Federal do Rio de Janeiro - Rio de Janeiro - Rio de Janeiro - Brasil
}

$\diamond$

\begin{abstract}
Resumo: O presente artigo situa as produções linguísticas dentro da categoria de trabalho, conforme Karl Marx apresenta em seus escritos. A linguagem, neste sentido, é vista como uma forma de trabalho em seus dois aspectos fundamentais: tanto como realização ontológica humana quanto como forma de alienação, entendida esta última também a partir dos textos de Marx. A esta forma de alienação, vinculam-se estreitamente os conceitos de ideologia e hegemonia, sobre os quais também apresentaremos algumas reflexões. Também nesse sentido, evidenciaremos algumas estratégias discursivas que constituem formas linguísticas alienadas. Reafirmamos assim a relevância dos estudos do discurso que se debruçam sobre a análise destas estratégias e de suas realizações materiais, que, por sua vez, engendram práticas sociais, legitimando e reproduzindo distintas formas de dominação.
\end{abstract}

Palavras-chave: Trabalho; Linguagem; Alienação; Ideologia

\begin{abstract}
The present article sets the linguistic productions into the category of work according to Marx's writings. Therefore, the language is seen as a form of work in its two fundamental aspects: both an ontological realization of the human being and a form of alienation, understanding this last one in a Marxist view. To this form of alienation is closely associated the concept of ideology and hegemony, about what we will present some reflexions. Moreover, we list several discursive strategies that contribute to the alienating characteristics the language may have. Finally, we reaffirm the relevance of the discourse studies as a form of analysis of these strategies and their material realizations, which engender social practices by legitimating and reproducing different forms of domination.
\end{abstract}

Keywords: Work; Language; Alienation; Ideology

Não são poucos os esforços no campo científico, especialmente no campo das chamadas "ciências naturais", no sentido de se compreenderem a fundo os componentes biológicos que determinam, em alguma medida, a vida do ser humano: almeja-se o descobrimento prévio de uma predisposição genética para determinada doença, a determinação precisa dos genes que supostamente levariam um indivíduo a desenvolver formas específicas de sexualidade e não de outras etc. Contudo, tais esforços trazem consigo uma limitação. Quando se debruça sobre a formação do homem em seus estágios mais iniciais com o objetivo de desvendar alguns de seus mecanismos universais, o investigador é levado a priorizar o elemento inato, imediatamente presente, sem qualquer preocupação fundamental sobre a história de sua aquisição. Vale dizer, tendemos a pensar o homem como um animal com imperativos naturais inquestionáveis como os de qualquer outra espécie. Fome e sede, dores físicas, instinto sexual, nenhum destes aspectos da constituição humana se submete a uma avaliação de caráter histórico. Assim sendo, somos levados a responder à clássica e recorrente questão: "mas o que nos diferenciaria dos outros animais?" com base em verificações empíricas do tipo "fotográfico", sem nos darmos conta de que nossa condição humana foi forjada num processo transcorrido num longo interregno histórico. Se somos apenas mais uma espécie entre tantas outras, o que nos levaria a construir gigantescos prédios para que em seguida os destruamos com base em motivações políticas e culturais, enquanto o joão-debarro dorme sossegado, seguro de que um outro de sua 
espécie não cometerá um ataque suicida lançando um bólido sequestrado contra seu lar? É possível responder a esta pergunta em termos exclusivamente fisiológicos? Pensamos que não, e invocamos no presente ensaio duas categorias que julgamos fundamentais para a reflexão sobre a constituição histórica do ser humano enquanto espécie ontologicamente distinta das demais no reino animal - as categorias do trabalho e da linguagem.

\section{Trabalho e linguagem: fundações ontológicas do homem}

Apoiando-nos numa tradição materialista-histórica, nosso trabalho parte de uma reflexão dos elementos fundamentais da fundação ontológica do homem, i.e., dos elementos que o diferencia dos outros animais. Há três momentos em que Karl Marx (1818-1883) nos dá subsídios para que compreendamos as especificidades do ser humano. Em A Ideologia Alemã (1845/1846), Marx e Engels (2001, p. 10-11) situam no momento de produção dos meios de sua subsistência os elementoschave que nos diferenciam das outras espécies animais. Neste momentos, Marx indica a centralidade da categoria do trabalho, estabelecida anteriormente nos Manuscritos económico-filosóficos de 1844. Neste último texto, a ideia da produção dos meios de subsistência associase à de uma forma específica de consciência. $\mathrm{O}$ animal distingue sua existência de sua atividade vital, enquanto que o homem "faz da sua atividade vital mesma um objeto da sua vontade e da sua consciência" (MARX, 2004, p.45). Em O Capital (1859), o pensador, já em fase madura, fixa a categoria do trabalho como elemento fundamental de toda a reflexão sobre o fazer humano. A matéria natural, colocada como uma força, faz com que o ser humano aproprie-se dela de modo útil para si, graças à sua própria condição física: "ao atuar por meio desse movimento sobre a Natureza externa a ele e ao modificála, ele modifica, ao mesmo tempo, sua própria natureza" (MARX, 1996, p. 297).

Esta modificação de sua natureza pressupõe ainda um outro elemento imprescindível a esta atividade: a consciência. Mais adiante, encontramos uma de suas mais célebres passagens:

Uma aranha executa operações semelhantes às do tecelão, e a abelha envergonha mais de um arquiteto humano com a construção dos favos de suas colmeias. Mas o que distingue, de antemão, o pior arquiteto da melhor abelha é que ele construiu o favo em sua cabeça, antes de construí-lo em cera. No fim do processo de trabalho obtém-se um resultado que já no início deste existiu na imaginação do trabalhador, e portanto idealmente. (Ibidem, p. 298)
Portanto, mais do que se apropriar de seus atributos corporais para modificar a natureza, e assim modificar a si próprio, o homem depende ainda de um componente ideal, uma determinada forma de consciência que lhe permita realizar uma "atividade vital lúcida" (id., 2004, p.45). György Lukács (1885-1971) retoma este aspecto da obra de Marx, ao aliar a atividade corporal humana à consciência, em vias de desenvolvimento: "o trabalho se torna não simplesmente um fato no qual se expressa a nova peculiaridade do ser social, mas, ao contrário, precisamente no plano ontológico, também se converte no modelo de toda a nova forma do ser" (LUKÁCS, 2009, p.230).

É relevante notar que há uma correlação direta entre a atividade material e a atividade da consciência do ser humano. Pode-se perguntar: qual dessas instâncias teria se desenvolvido primeiro? Segundo Lukács,

[a] essência do trabalho consiste precisamente em ir além dessa estabilização dos seres vivos na competição biológica com seu meio ambiente. O momento essencial da separação é constituído não pela fabricação de produtos, mas pelo papel da consciência, a qual, precisamente aqui, deixa de ser mero epifenômeno da reprodução biológica: o produto, diz Marx, é um resultado que já no início do processo existia "na representação do trabalhador", isto é, no plano ideal. (Ibidem, p. 228)

Friedrich Engels (1820-1895) também nos apresenta reflexões caras sobre nosso questionamento. Em seu Transformação do macaco em homem ${ }^{1}$, o autor alemão, já logo de início, reafirma a relevância ontológica da categoria do trabalho: "foi o trabalho quem criou o próprio homem” (ENGELS, 1980, p. 7). A composição corporal do ser humano também é referida por Engels como sendo a responsável por extrair elementos da natureza para então transformá-los em instrumentos a serem utilizados no trabalho. Prossegue o autor: foi através do desenvolvimento das distintas formas de trabalho entre os indivíduos da espécie humana que passou a existir então uma situação em que seus vínculos se tornavam mais e mais estreitos, por circunstâncias nas quais a cooperação e ajuda mútua se faziam necessárias. Com isto, "os homens em formação atingiram um ponto em que tinham qualquer coisa a dizer uns aos outros" (ibidem, p. 11). Decorre a partir daí um processo de desenvolvimento em conjunto do trabalho, dos sentidos, da consciência e até

\footnotetext{
Esta tradução para o português do título alemão original Anteil der Arbeit an der Menschwerdung des Affen deixa de lado o sintagma "Anteil der Arbeit" ("Parcela do trabalho"), o que configura um erro notável. O título correto, e que valoriza precisamente o trabalho na constituição humana, deveria ser Parcela de trabalho na hominização do macaco.
} 
mesmo do próprio cérebro ${ }^{2}$, até que o aperfeiçoamento destes pôde estabelecer uma diferenciação definitiva do homem com relação ao macaco. O resultado foi o "novo elemento que surgiu com o aparecimento do homem acabado: a sociedade" (ibidem, p. 13).

Algo de novo surge para nós nesse momento, e diz respeito à linguagem em sua relação direta com o desenvolvimento humano, possibilitada por sua atividade laboral. Quais relações podemos estabelecer entre o surgimento de uma instância de sociabilidade humana e as suas formas de linguagem? Recorremos a Bakhtin (1895-1975) para refletir sobre a questão.

Em seu Marxismo e Filosofia da Linguagem, BakhtinVoloshinov $^{3}$ (2009, original de 1929), estabelece, de modo propositalmente dicotômico e arbitrário, duas orientações do pensamento filosófico linguístico à época antecedente à constituição do campo das ciências da linguagem, tomando-os como ponto de partida para a sua reflexão: o subjetivismo individualista e o objetivismo abstrato. Em síntese: enquanto o subjetivismo individualista situa no indivíduo (i.e., em sua psicologia singular) as leis da criação linguística, o objetivismo abstrato considera a língua como um sistema objetivo e estável, a despeito de quaisquer atos individuais de fala, entendidos apenas como "simples refrações" das formas normativas (ibidem, p. 85). Neste sentido, Bakhtin concebe a linguagem como situada em um determinado ambiente sócio-histórico definido. A compreensão da linguagem deve partir especificamente deste ambiente. Em suas palavras, "[a] situação social mais imediata e o meio social mais amplo determinam completamente e, por assim dizer, a partir do seu próprio interior, a estrutura da enunciação" (ibidem, p. 117). É partindo desta primazia da natureza social de qualquer interação verbal que o autor afirmará que os signos, enquanto produtos ideológicos, têm surgimento somente em um "terreno interindividual":

[...] não basta colocar face a face dois homo sapiens quaisquer para que os signos se constituam. É fundamental que esses dois indivíduos estejam socialmente organizados, que formem um grupo (uma unidade social): só assim um sistema de signos pode constituirse. A consciência individual não só nada pode explicar, mas, ao contrário, deve ela própria ser explicada a partir do meio ideológico e social. (Ibidem, p. 35)

\footnotetext{
2 A afirmação de Engels carece ainda de uma afirmação definitiva por parte da ciência. Não se pode ainda atestar que as interações sociais possam ter causado modificações nas estruturas do cérebro, conquanto alguns estudos sugiram uma correlação entre estas estruturas e a extensão das redes sociais de alguns macacos, como, por exemplo, o artigo Social Network Size Affects Neural Circuits in Macaques (SALLET et al., 2011), publicado na revista Science.

3 Como se sabe, a atribuição da autoria desta obra a Bakhtin é controversa. Embora pareça-nos válido falar em círculo bakhtiniano, ainda que se possa apontar distinções entre cada um dos autores a ele pertencentes (Bakhtin, Voloshinov e Medvedev), atribuímos, para efeito de simplificação, a autoria a Bakhtin.
}

A despeito de outras reflexões acerca do signo presentes na obra, o que nos cabe por hora é entender que, para Bakhtin, as trocas linguísticas e o desenvolvimento da consciência dependem de uma organização social prévia. E, se esta organização, enquanto efeito da fundação ontológica do ser social, depende do trabalho humano, podemos então contrapor Bakhtin a Lukács quanto à antecedência cronológica dos dois momentos. $\mathrm{O}$ que teria surgido primeiro, a atividade material diante da natureza ou o desenvolvimento da consciência? Bakhtin se aproxima da perspectiva adotada por Engels:

Primeiro o trabalho, e depois em simultaneidade com ele, a linguagem; eis os dois principais estímulos sob cuja influência o cérebro do macaco se foi, pouco a pouco, transformando em cérebro humano, que, a despeito de todas as semelhanças, o supera de longe, quer em dimensão, quer em perfeição. (ENGELS, op. cit., p. 12)

Considerando a afirmação de Bakhtin, podemos dizer que a linguagem se produz em um meio social concreto e determinado, e que, portanto, este representa condição sine qua non para o desenvolvimento daquela.

Até o momento, trabalhamos com dois conceitos que não necessariamente são intercambiáveis: a consciência e a linguagem. Novas questões se tornam imediatamente latentes: a consciência depende da linguagem? Há algum tipo de forma de pensamento desprovido de uma constituição linguística? Para tentarmos responder a estas perguntas, trazemos algumas reflexões de Lev S. Vygotsky (1896-1934).

Em seu Pensamento e Linguagem, o autor se baseia em uma série de estudos anteriormente realizados com macacos e crianças, e chega a determinadas conclusões. Em primeiro lugar, Vygotsky destaca que o pensamento e a linguagem possuem raízes genéticas distintas, isto é, além de poderem ser considerados como elementos não necessariamente interligados, ambos desenvolvem-se "ao longo de trajetórias diferentes e independentes" (VYGOTSKY, 2005, p.51). Assim, segundo Jobim e Souza (1994, p.127), "ficou evidente para ele que a relação intrínseca entre pensamento e palavra não é uma condição prévia para o desenvolvimento da consciência humana, mas antes um produto desse desenvolvimento". Ademais, Vygostky sustenta que haja para a criança pequena uma fase inicial em que o pensamento é nãoverbal e a linguagem é não-intelectual (cf. ibidem, p. 61). Assim, não haveria para o autor a priori um vínculo de dependência entre pensamento e linguagem. $\mathrm{O}$ que não significa dizer que, já nas fases mais avançadas do desenvolvimento da criança, estes dois elementos não se encontrem, tornando-se assim o pensamento verbal e a linguagem racional (cf. ibidem, p. 54). Como se daria este encontro? Vygotsky responde: 
Se compararmos o desenvolvimento inicial da fala e do intelecto - que, como vimos, se desenvolvem ao longo de linhas diferentes tanto nos animais como nas muito novas - com o desenvolvimento da fala interior e do pensamento verbal, devemos concluir que o último estágio não é uma simples continuação do primeiro. $A$ natureza do próprio desenvolvimento se transforma, do biológico para o sócio-histórico. O pensamento verbal não é uma forma de comportamento natural e inata, mas é determinado pelo processo histórico-cultural e tem propriedades e leis específicas que não podem ser encontradas nas formas naturais de pensamento e fala. (Ibidem, p. 63)

Nisto reside, ao nosso ver, uma das maiores contribuições do cientista bielo-russo, que situa o desenvolvimento da consciência e do pensamento da criança nas interações linguísticas desenvolvidas ao longo da história individual daquela - assumindo o pensamento seu caráter verbal por volta dos dois anos de idade.

Consideramos que a linguagem é uma forma de trabalho e, enquanto tal, se constitui como elemento ontológico fundador do ser humano. Aqui evocamos a obra de um autor ainda pouco conhecido por seus estudos linguísticos, mas de grande importância para nosso trabalho. Trata-se de Ferruccio Rossi-Landi (1920-1985), filósofo italiano autor de A linguagem como trabalho $e$ como mercado - uma teoria da produção e da alienação linguísticas.

Rossi-Landi parte do princípio de que as palavras e as mensagens não gozam de uma existência própria em estado natural, sendo elas o resultado de uma produção do trabalho humano, o que nos possibilita falar em "trabalho humano linguístico" (ROSSI-LANDI, 1985, p. 64). Abre-se, assim, uma nova possibilidade de reflexão: não cabe mais falarmos de uma distinção entre o trabalho e a linguagem - a última é uma forma do primeiro, e ambos distinguem o homem dos outros animais. Nas palavras do autor italiano:

Pretende-se aqui tornar unitária a definição do homem enquanto animal falante e trabalhador, que se diferencia de todos os outros, na medida em que produz instrumentos e palavras [...], e com essa produção, que constitui "o social", ele forma historicamente a si próprio. (Ibidem, p. 65-66)

Ecoam claramente neste fragmento de modo muito claro as ideias de base marxiana anteriormente apresentadas. Rossi-Landi mostra-se ainda mais próximo de Vygotsky ao considerar o caráter histórico da linguagem e ao afirmar que, não fossem as línguas um produto da linguagem (entendida como forma de trabalho), pertenceriam a uma estrutura puramente biológica, "como a digestão ou a respiração". Seriam, assim, "hipohistóricas" (ibidem, p. 67).

$\mathrm{O}$ autor italiano afirma também que as línguas desenvolvem-se " $n a$ dialética da satisfação das necessidades, ou seja, dentro do processo de instituição das relações de trabalho e de produção" (ibidem, p. 8). De modo similar a Engels, quanto à questão da necessidade da comunicação - Rossi-Landi verifica que, em dado momento, o homem passou a ter o que dizer. Assim, não caberia o questionamento se os signos ou os instrumentos físicos (enquanto formas de extensão do corpo humano) surgem primeiro, pois, enquanto fenômeno social, a própria mente abarca em sua constituição ambos os elementos, sendo justamente por eles formada (ibidem, p. 73).

Contrapomos, contudo, esta última afirmação às teses de Michael C. Corballis (1936), pesquisador no campo da neurociência cognitiva. Em sua obra The Lopsided Ape Evolution of the generative mind, Corballis afirma que, independentemente de consideramos a linguagem humana como resultado de uma reorganização genética específica ou de um movimento gradual e contínuo de mudanças, ela surge historicamente, na cronologia do desenvolvimento da espécie humana, em um momento posterior àquele em que as ferramentas começam a ser fabricadas. Ademais, o autor sugere que a esta altura de nosso processo evolutivo já se encontrariam constituídas sociedades organizadas de forma hierárquica e com indivíduos exercendo em seu interior papéis distintos (CORBALLIS, 1991, p. 306 et seq.).

Considerando o exposto até aqui, podemos chegar a algumas conclusões. Em síntese: enquanto forma de ação humana que transforma e subjuga a natureza, com vistas a atender as suas necessidades de subsistência, é o trabalho que faz com que o homem protagonize um estágio evolutivo que o diferencia dos outros animais, fundando ontologicamente a si próprio como um ser social. Não se pode estabelecer ainda com precisão o momento da história em que o ser humano adquiriu a linguagem, sendo, entretanto, possível dizer que seu surgimento precede o trabalho material da manufatura de ferramentas. Retomando Vygotsky, parece-nos cabível traçarmos um paralelo entre os longos períodos da história evolutiva do homem e a "fase pré-intelectual da linguagem" (cf. JOBIM e SOUZA, 1994, p. 128), em que a consciência humana, tal como a consciência da criança, encontrar-seia ainda não verbalizada, até se tornar plenamente verbal e racional. A despeito da ordem de seu surgimento - uma vez estando presentes em meio a uma organização social constituída por trabalho, consciência e linguagem cada vez mais complexos - todos estes elementos passaram a se desenvolver um a partir do outro, em imbricações cada vez mais firmes. Assim, como conclusão fundamental até o momento, pontuamos que a linguagem, como 
forma específica de trabalho, é também responsável pela fundação ontológica do homem.

\section{Linguagem alienada, ideologia e hegemonia}

Seguindo a metodologia materialista de Marx, ao se falar em trabalho enquanto forma de desenvolvimento da potencialidade humana há que se considerar também seu caráter negativo: sua forma alienada. Isto é, é possível que haja uma forma de trabalho cujo produto se torne estranho a seu produtor, passando a não mais a lhe pertencer.

O conceito de alienação era já presente na obra de Hegel, filósofo alemão anterior a Marx, e sobre cujo pensamento exerceu considerável influência. Dito de modo bastante resumido, a alienação para Hegel é um processo do desenvolvimento espiritual do homem que faz com que ele supere seu estágio natural inicial através de seu trabalho - reflexão esta que concede as bases da primazia do trabalho em Marx na constituição ontológica do ser humano. Hegel, porém, segundo Marx, considera apenas o trabalho intelectual abstrato, não atentando para seu aspecto negativo (MARX, 2004, p.24). Segundo Santos da Luz e Bavaresco (2010, p. 143), Hegel, mesmo entendendo o trabalho como "um ato de produção de si do homem, não consegue concebê-lo em sua objetividade, como uma atividade que pode estar alienada em relação àquele ser humano que a executa".

Marx irá perceber que, no sistema capitalista de produção, o desenvolvimento das potencialidades humanas possibilitadas pelo trabalho é tolhido em decorrência da apropriação do trabalho do homem pelo próprio homem. O trabalhador, em sua relação com o produto de seu trabalho, vê neste um objeto estranho, que se lhe torna um poder autônomo, e que se lhe opõe de forma hostil e antagônica (cf. MARX, 2004, p. 81).

O trabalho alienado, como aponta Ollman (1976), implica transformações na relação do homem com sua atividade produtiva, com seu produto, com seus semelhantes, e com sua própria espécie. No que respeita a sua atividade, o trabalhador, graças à divisão social do trabalho, passa a participar somente de uma pequena etapa do processo da produção, exercendo um trabalho específico e repetitivo, podendo sua atividade mecânica ser comparada à de uma máquina. Quanto à relação com o seu produto de seu trabalho, enquanto propriedade do capitalista, se torna para o trabalhador uma objetivação que lhe é estranha e que não pode ser usado por ele em atividade produtiva posterior - e isto considerando ainda que o produto em si já é alienado na medida em que provém anteriormente de uma atividade por sua vez também alienada. No que respeita à relação com seus semelhantes, o fato de o produto do trabalho estar em poder do capitalista faz com que os interesses entre este último e os trabalhadores se tornem distintos, determinando assim um contexto social que engendra o antagonismo de classe. Por fim, no que concerne a relação do trabalhador com sua própria espécie, Marx aponta para o fato de que sua vida, cujas possibilidades criativas poderiam se desenvolver de forma mais plena a partir de um trabalho de caráter positivo, se reduz à ação de mera sobrevivência, limitada cada vez mais às necessidades de vida mais elementares como beber, comer, procriar etc. (MARX, 2004, p. 83).

A partir do que apresentamos sobre trabalho alienado, colocamos a questão: se a linguagem é uma forma específica de trabalho, qual seria sua forma negativa e alienada?

Um primeiro aspecto desta problemática que podemos destacar é com relação a uma possível dimensão do trabalho linguístico que se constitua como algo alienado para o falante individual. Para Rossi-Landi, esta alienação é um aspecto inerente e indissociável de todo processo de produção linguística no que diz respeito às suas estruturas internas, isto é, ao seu componente sistêmico. Para o autor, o indivíduo é compelido já desde o nascimento a utilizar os produtos do trabalho linguístico já existentes e a partir de modelos que lhe são anteriores. Os processos que subjazem à criação linguística não podem ser por ele modificados:

[...] o trabalhador linguístico acaba encontrando-se na situação de não saber $o$ que $f a z$ quando fala, de não saber porque fala como fala e de pertencer a processos de produção linguística que o condicionam desde o começo, que o obrigam a ver o mundo de determinadas maneiras e que the tornam difícil o trabalho original ou, simplesmente, diferente. (ROSSI-LANDI, 1985, p. 104-105)

Para nós, a alienação não se dá na esfera estrutural da língua. Não consideramos possível entender a produção linguística como um fenômeno alheio ao indivíduo no que tange seus mecanismos mais internos e estruturais. Por dois motivos. Como sugerem os estudos no campo da neurociência ou ainda aqueles desenvolvidos por Noam Chomsky e sua Gramática Universal (CHOMSKY, 1980, p.28), não nos parece cabível elidir os componentes de natureza biológica comuns a todo e qualquer indivíduo (à exceção de casos de afasias e similares) que possibilitam a faculdade da linguagem. Ademais, toda produção da parole, no sentido saussuriano (SAUSSURE, 2006, p.28), é um ato individual, próprio e único, não podendo ser alienado de seu produtor. Isto é, as estruturas internas não são estranhas ao falante individual - não é na esfera do sistema que devemos tratar da alienação. 
$\mathrm{Na}$ análise marxiana, a apropriação do trabalho pelo capitalista é um aspecto fundamental em sua definição de alienação. Podemos de forma homóloga supor que haja uma expressão linguística desta forma de apropriação? Cremos que sim.

No fragmento supracitado, Rossi-Landi já nos aponta para maneiras "de ver o mundo": a alienação ao nível linguístico vincula-se a estas maneiras, anteriores aos indivíduos, e que lhe são estranhas. Trata-se então aqui de uma relação estreita entre a ideologia e a alienação nas formas linguísticas.

Para nos apropriarmos do conceito de ideologia, é necessário a definição precisa de sua compreensão e operacionalização em cada momento de nossas reflexões, dada a pluralidade de sentidos que lhe têm sido concedida ao longo da história por diferentes autores. Em seu artigo Uma abordagem da ideologia (1987), o autor italiano nos apresenta três grupos principais de significados do conceito de ideologia. Tais significados certamente não esgotam a questão, mas nos parecem relevantes para apontar os seus principais matizes. São eles: ideologia como ciência das ideias, ideologia como visão de mundo e ideologia como falso pensamento. O primeiro remete às origens do termo, a partir de Destutt de Tracy, filósofo parisiense que tinha como intuito fundar uma ciência das ideias, imbuído ainda pela ilusão da neutralidade da ciência no tratamento de seus objetos. $\mathrm{O}$ segundo significado traz consigo a neutralização do conceito na medida em que diz respeito ao conjunto de ideias e formas de compreensão da realidade social de um determinado grupo historicamente situado. Neste sentido, a ideologia não é positiva nem negativa, mas apenas um agrupamento de elementos ideais. Por fim, a terceira acepção de RossiLandi nos remete a Marx, para quem as ideias dominantes de uma sociedade em um determinado momento histórico são precisamente as ideias da classe dominante, visto que é ela que dispõe das condições materiais reais que permitem uma produção de formas de consciência que as legitimam. As ideias tendem a não apresentar de forma explícita as relações materiais concretas que se estabelecem entre os homens e que instauram uma relação de dominação - daí o caráter de falseamento. Resumindo, temos três valorações para o termo ideologia: positiva, neutra e negativa. É sobre esta última que nos debruçaremos.

John B. Thompson (1951), em sua obra Ideology and Modern Culture, tal como Rossi-Landi, aponta para dois tipos gerais da concepção de ideologia: as concepções neutras e as concepções críticas. Quanto às primeiras, não há o que acrescentarmos. As segundas é que nos interessam mais de perto. Após traçar um histórico dos usos do conceito, o autor especifica aquele que mais lhe interessa em seus estudos. Thompson alinha-se à concepção crítica da ideologia, uma vez que sua análise se preocupa com a maneira com a qual as formas simbólicas - elementos constituintes da ideologia e que dispõem de elementos verbais e não-verbais - estabelecem e sustentam as relações de poder (THOMPSON, 2002, p.85). Com isto, para o autor não cabe contrapor falsidade à realidade, como observamos anteriormente em Rossi-Landi - ou mesmo em Marx. Para Thompson, o que interessa no exame da ideologia é a vinculação das formas simbólicas - i.e., da linguagem - com estruturas sociais de dominação e de poder. E, ao tematizar formas de dominação, o autor não se limita ao âmbito das classes, como nos sugeriram inicialmente os estudos marxistas clássicos. Para Thompson, as relações entre diferentes gêneros, etnias ou Estados-nação (hegemônicos e periféricos) também constituem relações de dominação que podem ser legitimadas através da ideologia (ibidem, p. 88).

Thompson nos diz ainda que as formas simbólicas, carregadas ou não de conteúdo ideológico, são partes constitutivas da realidade social, que criam e sustentam as relações entre indivíduos ou grupos. No entanto, o trato das formas materiais da ideologia não foi exclusividade de Thompson, e se encontra também nas reflexões de Louis Althusser (1918-1990). O autor francês, ao discorrer sobre sua concepção de ideologia em sua obra Aparelhos Ideológicos do Estado, destaca em uma de suas "teses" que a "ideologia tem uma existência material" e vincula-se a práticas e rituais (ALTHUSSER, 2007, p. 88 et seq.). Em suma, o que nos interessa nos dois autores aqui é que estes estabelecem uma relação direta entre comportamentos, atos e atitudes tomadas pelos indivíduos em sua vida social e as formas de consciência e representações simbólicas que os promovem. Compreender a linguagem significa compreender as ações sociais concretas por ela engendradas. Trata de estabelecer uma relação dialética entre cada contexto histórico concreto e suas condições materiais e as formas simbólicas que o atravessam. Se por um lado evitamos a todo custo o determinismo econômico mecanicista, por outro não podemos desconsiderar as circunstâncias não-discursivas e seus impactos nas práticas simbólicas humanas, e em particular as práticas verbais, por efeito de uma compreensão do fenômeno ideológico que o reduz exclusivamente a questões de natureza discursiva.

Com isto, podemos já sintetizar a problemática deste breve ensaio da seguinte forma: nos apropriamos do conceito de ideologia como um conjunto de formas simbólicas que na vida social instauram ou dão continuidade a relações assimétricas de poder e de dominação entre grupos sociais, esta exercida além do âmbito exclusivo das classes socioeconômicas. Entendemos ainda formas simbólicas como quaisquer formas de linguagem, isto é, como construtos significativos (THOMPSON, 2002, p. 89) 
que gozam de materialidade e que se relacionam a rituais e práticas sociais. Podemos, assim, esboçar em termos mais claros as relações entre linguagem, alienação e ideologia.

Em primeiro lugar, retomando as reflexões iniciais do nosso trabalho, vimos que a linguagem é ela mesma uma forma de trabalho humano, e que, como tal, goza de um caráter ontológico fundador. Enquanto trabalho, contudo, ela pode adquirir uma valoração negativa, na medida em que se torna alienada. Por alienação, vimos que se trata de uma condição de estranhamento do trabalhador diante do produto de seu trabalho, por sua vez apoderado pelo capitalista, dadas as relações entre o capital e o trabalho na organização política e econômica de nossa sociedade contemporânea. Mutatis mutandis, a apropriação capitalista do trabalho alheio permanece em sua essência a mesma da época de Marx. Questionamos, então: no que consiste, especificamente, a alienação linguística? Esta, conforme cremos, consiste na produção de formas simbólicas que, em vez de descortinarem os mecanismos contemporâneos de apropriação do trabalho alheio, mascaram discursivamente suas verdadeiras causas - tornam-se, portanto ideológicas, no sentido aqui adotado.

Como vimos, esta forma de alienação não consiste em um estranhamento a partir das estruturas primeiras da língua enquanto sistema; não se trata da perda da posse da parole, da faculdade da enunciação linguística individual, mas do aprisionamento do sujeito em uma estrutura material e discursiva com o qual se é levado a reproduzir "voluntariamente" formas simbólicas ideológicas. Isto, pois

[...] quem se encontra na posição de remetente é a própria classe dominante, que impõe a si mesma e às outras classes a aceitação de certos sistemas de signos em lugar de outros; ou então se trata de remetentes subordinados que, submetidos pela classe dominante, limitam-se a utilizar seus códigos ou então calam-se (ROSSI-LANDI, 1985, p. 41).

Não se trata aqui de qualquer forma de determinismo, mas de reconhecer a eficácia das forças discursivas e ideológicas na manutenção de circunstâncias sociais que assegurem assimetrias de poder entre diferentes grupos sociais. Eficácia esta, por sua vez, que não se materializa em atos necessariamente conscientes e voluntários por parte dos dominantes. Estes também são com frequência aprisionados nestes processos ideológicos.

Em suma, uma produção linguística alienada é uma produção linguística ideológica - como vimos, em termos negativos (cf. THOMPSON, passim). Contudo, se a apropriação do trabalho alheio se dá pela via de uma práxis involuntária, o mesmo não podemos dizer do processo de produção linguística alienada.

Neste aspecto, devemos ir além de Marx. Quando da redação dos Manuscritos, o filósofo alemão pontuava enfaticamente a infelicidade do trabalhador em suas atividades alienadas, assim como o seu caráter compulsório, visto que, no sistema capitalista à sua época, nem mesmo as necessidades mais básicas de subsistência podiam ser satisfeitas sem que o trabalhador se submetesse a tais formas de alienação (MARX, 2004, p. 82-83). Contudo, poderíamos hoje estabelecer um paralelo entre o trabalho alienado e suas expressões linguísticas ideologizadas, afirmando o caráter compulsório de ambas as práticas? Salta-nos à vista que não.

Marx apontava para o caráter involuntário do trabalho - o trabalhador não dispunha de poder absoluto de escolha para poder realizar as tarefas que deseja e, com isto, garantir sua subsistência. Com isto, o autor afirmava então indiretamente que não se punha como questão social as formas, que conhecemos hoje, de consentimento ou convencimento. $\mathrm{Na}$ atualidade, contudo, estas formas encontram-se implicadas no processo de alienação linguística vinculados com mecanismos de produção e obtenção de consenso (cf. DÍAZ-SALAZAR, 1991, p.240) - o que nos remete aqui ao conceito gramsciano de hegemonia.

Como sabemos, Antonio Gramsci (1891-1937) foi um pensador italiano de grande relevância na retomada de problemáticas postas pelo pensamento marxiano no início do século XX. Na altura das primeiras décadas do século passado, observava-se (particularmente nas fileiras social-democratas alemãs e austríacas) uma apropriação claramente mecanicista da obra de Marx. Postulava-se teoricamente a transição para a sociedade socialista como um resultado quase que exclusivo das transformações na estrutura econômica da sociedade e de suas forças produtivas. Em função do caráter determinista desta postulação, as formas superestruturais (políticas, culturais, artísticas etc.) eram postulados teoricamente como simples reflexos da estrutura econômica. Em oposição a isto, o pensamento de Gramsci entrevia também nestas formas superestruturais um espaço de conflito e de disputa entre classes. Neste espaço, observa Gramsci, a burguesia exerce uma hegemonia simbólica que lhe mantém assegurada a hegemonia material sobre as forças de trabalho. O filósofo italiano percebia que não se podia falar em uma dominação política sem que se levasse em conta forma de direcionamento social (DÍAZ-SALAZAR, 1991, p.228). Este sentido de direcionamento, condução, está presente nas origens etimológicas do termo hegemonia - do grego eghesthai - de que parte Gramsci. Dito de modo muito bem sintetizado: 
$\mathrm{Na}$ história da luta de classes, a hegemonia de uma classe depende, essencialmente, do modo como seu domínio sobre a produção material e sobre o conjunto das forças produtivas e destrutivas se desenvolve como domínio sobre a produção e a circulação de ideias, sobre a formação da consciência socialmente determinada e, consequentemente, sobre o conjunto de organizações e instituições da sociedade civil e sobre o poder político do Estado. Sem isso, o domínio de uma classe social sobre os meios da produção social da vida teria de se afirmar permanentemente pela coerção e pela violência; não caberia, neste caso, falar em hegemonia, mas em dominação direta, exercida permanentemente pelos meios mais brutais. (DANTAS, 2008, p. 92-93)

$\mathrm{O}$ conceito de hegemonia assume no pensamento gramsciano características fundamentais para as reflexões que desenvolvemos no presente trabalho. Destacamos aqui, inicialmente, a vinculação dialética existente entre uma dada estrutura econômica que engendra relações de dominação entre diferentes grupos ou classes sociais e as formas de produção de consciência que coagulam simbolicamente estas mesmas relações - sem as quais, inclusive, não poderiam se constituir. Portanto, não consideramos possível a desvinculação teórica da linguagem das circunstâncias históricas de luta e de dominação nas quais é produzida. O que há de novo que tomamos do pensamento de Gramsci é a importância por ele concedida ao componente superestrutural, do qual destacamos a linguagem em sua materialidade concreta i.e., o discurso - para a compreensão das relações sociais de poder. No dizer do grande teórico italiano,

[...] podem-se fixar dois grandes "planos" superestruturais: o que pode ser chamado de "sociedade civil" (isto é, o conjunto de organismos designados vulgarmente como "privados") e o da "sociedade política ou Estado", planos que correspondem, respectivamente, à função de "hegemonia" que o grupo dominante exerce em toda a sociedade e àquela de "domínio direto" ou de comando, que se expressa no Estado e no governo "jurídico". (GRAMSCI, 2001, p. 20-21)

É necessário ir além de qualquer generalidade simbólica: quando falamos em alienação linguística, falamos em formas verbais que possibilitam uma aceitação consensual de um determinado status quo: o trabalho linguístico alienado é um trabalho voluntário e que assume na contemporaneidade extrema importância quando comparado com o momento histórico vivido por Marx - haja vista o caráter hipersemiotizado de nossa pós-modernidade. Em suma, o que afirmamos aqui é: uma produção linguística alienada, i.e. ideológica, integrase aos mecanismos com os quais uma classe ou grupos sociais dominantes exercem sua hegemonia sobre outros em um determinado momento histórico.

Cabe agora a pergunta: como identificar concretamente uma forma linguística alienada? Em quais mecanismos concretos ela se realiza?

Não cabe nos limites deste trabalho a apresentação minimamente sistemática de exemplos linguísticos de alguns destes mecanismos - alguns dos quais já sistematicamente estudados ${ }^{4}$. Thompson (2002, p.91) nos apresenta de forma não exclusiva modos de operação da ideologia que constituem um precioso norte para a análise e verificação dos mesmos. Estes modos gerais associam-se a estratégias de construção simbólica. Mencionemos, entretanto, um exemplo próprio. Quando nos deparamos com enunciados como "o homem é egoísta e explorador por natureza, e nada podemos fazer para mudar esta condição", percebemos um mecanismo concreto de reificação. Para Resende e Ramalho (2006, p. 52), trata-se da "retratação de uma situação transitória como permanente e natural" através da estratégia da eternalização, em que "fenômenos sócio-históricos [são] apresentados como permanentes". Outro aspecto que merece destaque é o uso alienado da "obviedade", por sua vez inalienável de seu componente discursivo e linguístico, conforme nos aponta Suelly Amaral Mello (1997). Segundo a autora, a obviedade se cristaliza como uma "característica ontológica da vida cotidiana". A exemplo do trabalho em Marx, a obviedade apresenta um duplo caráter, ao mesmo tempo positivo e negativo. Positivo, uma vez que há "necessidades prático-utilitárias" que exigem "automatismos necessários à realização do volumoso conjunto de atividades que compõem a rotina indispensável da vida cotidiana" (ibidem, p. 113). Contudo, e nisto reside o seu caráter negativo, na esfera do não-cotidiano, na qual se exige uma "atitude dirigida intencionalmente pela consciência” (ibidem, p.114), a obviedade limita o homem em sua compreensão das atividades humanas que se situam num plano além da vida cotidiana, como nos campos da ciência, das artes, da filosofia etc. Percebem-se aí os mesmos efeitos alienantes que Marx percebeu na construção conceito do trabalho, e que se estendem até o âmbito das produções linguísticas:

[...] o homem alienado toma a vida cotidiana como se fosse a possibilidade máxima para a existência humana, e as formas do pensamento cotidiano como sendo as únicas formas de pensamento existentes e, por isso, modelo para todas as atividades humanas. (Ibidem, p. 115)

\footnotetext{
4 Destacamos neste particular a obra de Norman Fairclough Analysing Discourse (2003).
} 


\section{Comentários finais. A relevância dos estudos discursivos}

Rossi-Landi (1985, p. 132) afirma que "a res da alienação não é natural mas sim histórico-social". Isto significa considerar a condição de alienação como passível de mudança ou mesmo de superação. Tal possibilidade se observava no pensamento de Marx.

O objetivo de nosso trabalho é situar a linguagem como mais um elemento de fundação ontológica do ser humano, e como forma de trabalho, passível, portanto, de assumir uma dimensão negativa. O que tematizamos aqui é o discurso como uma categoria ontológica fundada no mundo do trabalho, constituído como uma unidade analítica que se apresenta como objeto de investigação científica. Norman Fairclough, um dos grandes expoentes da chamada Análise Crítica do Discurso, nos apresenta uma boa definição para esta unidade analítica:

\begin{abstract}
Ao usar o termo "discurso", proponho considerar o uso de linguagem como forma de prática social e não como atividade puramente individual ou reflexo de variáveis situacionais. [...] [Isto] implica ser o discurso um modo de ação, uma forma em que as pessoas podem agir sobre o mundo e especialmente sobre os outros, como também um modo de representação. [...] implica uma relação dialética entre o discurso a estrutura social, existindo mais geralmente tal relação entre a prática social e a estrutura social: a última é tanto uma condição quanto o efeito da primeira. Por outro lado, o discurso é moldado e restringido pela estrutura social no sentido mais amplo e em todos os níveis: pela classe e por outras relações sociais em um nível societário, pelas relações específicas em instituições particulares como o direito ou a educação, por sistemas de classificação, por várias normas e convenções, tanto de natureza discursiva como não discursiva, e assim por diante. (FAIRCLOUGH, 2001, p.90-91)
\end{abstract}

Esta valorização do componente linguístico, conforme apontamos, emana da indiscutível relevância por ele assumida na contemporaneidade. Quando consideramos todas as transformações ocorridas ao longo das últimas décadas no campo das comunicações, que instauraram a dita "era da informação", torna-se óbvio para nós que é na esfera dos discursos, das superestruturas que as formas de organização materiais de uma sociedade e as assimetrias de poder por elas produzidas encontram crescentemente espaços estratégicos de legitimação e reprodução. Desta forma, parece-nos claro que o campo dos estudos da linguagem requer um conhecimento mais apurado sobre noções basilares quanto à sua natureza, indissociável do mundo da produção material, e do trabalho humano.
Uma abordagem materialista da linguagem e de suas manifestações discursivas poderia emprestar às ciências linguísticas funções éticas claramente empoderadoras de todas as classes e segmentos humanos historicamente explorados, desapropriados em escalas macro ou microssociais dos próprios bens produzidos, despertando-os para lutas emancipatórias em torno de interesses que, sem o seu auxílio epistêmico, permaneceriam inobservados. Não é, porém, o que se costuma observar. Se consideramos o desenvolvimento recente deste campo no interior das ciências ditas humanas, percebemos que, conquanto seja evidente a natureza social da linguagem, suas produções vêem-se com frequência analisadas como objetos destituídos de alguns de elementos fundamentais na constituição ontológica humana. $\mathrm{O}$ trabalho humano concreto, em seus componentes materiais irredutíveis - como as forças produtivas (o produtor, os meios tecnológicos de que dispõe e os objetos naturais a serem transformados) e as relações de produção (formas administrativas, políticas e sociais assumidos pelo processo produtivo) -, que formaram e formam (atualmente em escala crescentemente fragmentada, o que torna cada um de seus momentos fundamentais cada vez mais invisíveis) a vida social, e sobredeterminam as criações simbólicas de nossa espécie, é com frequência suprimido em termos analíticos. As ciências da linguagem, com alguma frequência inusitada, apagam, já em seus pressupostos teóricos e metodológicos, alguns traços ontológicos básicos da espécie humana na investigação de sua comunicação verbal.

Colocada como problema, ao qual nos referimos no início deste ensaio, a profundidade histórica, no processo de constituição ontológica do ser humano, tem que ser vista como dimensão ineliminável nos estudos sobre a linguagem humana. Quando a linguagem humana e suas manifestações concretas - os discursos - são isolados, e transformados metodologicamente em objetos semióticos abstratos, desprovidos dessa historicidade, amesquinhase inadvertidamente o trabalho, expressão máxima da existência humana, e, dessa forma, amesquinham-se a própria investigação linguística. Ao tematizarmos a linguagem como homóloga ao trabalho, no processo histórico de formação da espécie humana, tematizamos necessariamente $\mathrm{o}$ aspecto da alienação e, como corolário, o da hegemonia. Com este breve ensaio, esperamos ter evidenciado alguns aspectos especificamente linguísticos em meio às tradições científicas que há mais de século se debruçam sobre a fenomenologia das falsas consciências e da alienação humana. Ao fazê-lo, esperamos também contribuir concretamente no sentido de sua superação. Pois, a utopia que perpassa o presente texto é a da crença na força social que a linguagem humana desprende em termos de energia, tanto na autoconstituição de indivíduos 
autônomos como na autoconstituição enquanto espécie não-alienada do fruto de suas produções materiais e simbólicas.

\section{Referências}

ALTHUSSER, Louis. Aparelhos ideológicos de Estado. Tradução Walter José Evangelista e Maria Laura Viveiros de Castro. 10. ed. Rio de Janeiro: Graal, 2007.

BAKHTIN, Mikhail. Marxismo e filosofia da linguagem: problemas fundamentais do método sociológico na ciência da linguagem. Tradução Michel Lahud e Yara Frateschi Vieira São Paulo: Hucitec, 2009.

CHOMSKY, Noam. Reflexões sobre a linguagem. Tradução Carlos Vogt, Cláudia Tereza Guimarães de Lemos, Maria Bernadete Abaurre Cnerre, Clarice Sabóia Madureira e Vera Lúcia Maia de Oliveira. São Paulo: Cultrix, 1980.

CORBALLIS, Michael C. The lopsided ape: evolution of the generative mind. New York: Oxford University Press, 1991.

DANTAS, Rodrigo. Ideologia, hegemonia e contra-hegemonia. In: COUTINHO, Eduardo Granja (Org.). Comunicação e contra-hegemonia. Rio de Janeiro: Editora UFRJ, 2008.

DÍAZ-SALAZAR, Rafael. El proyecto de Gramsci. Barcelona: Anthropos; Madrid: Hoac, 1991.

ENGELS, Friedrich. Quota-parte do trabalho na hominização do macaco. Tradução José Barata-Moura. In: MARX, Karl; ENGELS, Friedrich. Obras Escolhidas em três tomos. Lisboa: Edições “Avante!”, 1985. Tomo III, p. 71-83.

FAIRCLOUGH, Norman. Discurso e mudança social. Tradução Izabel Magalhães. Brasília: Editora UNB, 2001.

FAIRCLOUGH, Norman. Analysing discourse. London: Routledge, 2003.

FARACO, Carlos Alberto. Linguagem e Diálogo - as ideias linguísticas do círculo de Bakhtin. Curitiba: Criar edições, 2003.

GRAMSCI, Antonio. Cadernos do cárcere. Tradução Carlos Nelson Coutinho. Rio de Janeiro: Civilização Brasileira, 2001. Vol. 2.

JOBIM E SOUZA, Solange. Infância e linguagem. Campinas, SP: Papirus, 1994.

LUKÁCS, György. O jovem Marx e outros escritos de filosofia. Tradução Carlos Nelson Coutinho. Rio de Janeiro: UFRJ, 2009.
MARX, Karl. O capital: crítica da economia politica. Tradução Regis Barbosa e Flávio R. Kothe. São Paulo: Nova Cultural, 1996.

MARX, Karl. Manuscritos econômico-filosóficos. Tradução Jesus Ranieri. São Paulo: Boitempo, 2004.

MARX, Karl; ENGELS, Friedrich. A ideologia alemã. Tradução Luis Claudio de Castro e Costa. São Paulo: Martins Fontes, 2001.

MELLO, Suelly Amaral. Linguagem e alienação da consciência. Alfa, São Paulo, v. 41, p. 109-131, 1997.

OLLMAN, Bertell. Alienation: Marx's conception of man in capitalist society. 2.ed. Cambridge; New York: Cambridge University Press, 1976.

RAJAGOPAlAN, Kanavillil. Por uma linguística crítica: linguagem, identidade e a questão ética. São Paulo: Parábola, 2003.

RESENDE, Viviane de Melo; RAMALHO, Viviane. Análise de discurso crítica. São Paulo: Contexto, 2006.

ROSSI-LANDI, Ferruccio. A linguagem como trabalho e como mercado. Tradução Aurora Fornoni Bernardini. São Paulo: Difel, 1985.

ROSSI-LANDI, Ferruccio. Uma abordagem da ideologia. Discurso - Revista do Departamento de Filosofia da FFLCH da USP, São Paulo, v. 16, p. 131-144, 1987.

SALLET, J. et al. Social network size affects neural circuits in macaques. Science, v. 334, n. 6056, p. 697-700, nov. 2011.

SANTOS DA LUZ, Ricardo; BAVARESCO, Agemir. Trabalho alienado em Marx e novas configurações do trabalho. Princípios, Natal, v. 17, n. 27, p. 137-165, jan.-jun. 2010.

SAUSSURE, Ferdinand de. Curso de linguística geral. Tradução Antônio Chelini, José Paulo Paes e Izidoro Blikstein. São Paulo: Cultrix, 2006.

THOMPSON, John Brookshire. Ideología y cultura moderna - teoría crítica social en la era de la comunicación de masas. México, D.F: Universidad Autónoma Metropolitana, Unidad Xochimilco, División de Ciencias Sociales y Humanidades, 2006.

VYGOTSKY, Lev Semenovitch. Pensamento e linguagem. Tradução Jefferson Luiz Camargo. São Paulo: Martins Fontes, 2005.

Recebido: 30 de novembro de 2013

Aprovado: 23 de março de 2014

Contato: industrial-noise@hotmail.com luiz.montez@gmail.com 